compound called agouti-

related peptide.

When the researchers deleted a gene required for autophagy in the mouse neurons that produce this peptide, the mice ate less and were slimmer than control animals with normal autophagy.

Cell Metab. 14, 173-183 (2011)

\section{MICROBIOLOGY}

\section{Biofilm for} yeast sex

Some microorganisms stick together to form impenetrable, drug-resistant biofilms that can contaminate surfaces such as those of medical devices. The yeast Candida albicans is one such microbe, but certain strains form another type of biofilm - one that is susceptible to drugs and is regulated by a different molecular pathway.

David Soll and his colleagues at the University of Iowa in Iowa City found that about $10 \%$ of C. albicans strains form this second type of biofilm, which is also permeable to immune cells. These strains have a genetic difference at one locus that allows the yeast to reproduce sexually. The authors suggest that this minority type of biofilm aids in the mating process by mediating the movement of hormone signals.

Comparing the different pathways that regulate the two types of biofilm could yield clues about what makes a biofilm drug-susceptible, which could aid in the development of treatments to disrupt harmful biofilms. PLoS Biol. 9, e1001117 (2011)

\section{CELL BIOLOGY}

\section{Alzheimer's in a dish}

Skin cells taken from patients with Alzheimer's disease and converted into neurons exhibit molecular defects that have been linked to the neurodegenerative condition.
Such cells could function as models for those working to understand the disease.

Asa Abeliovich at Columbia University in New York and his colleagues created neurons from the fibroblasts of three patients with genetic mutations that cause a rare hereditary form of Alzheimer's disease. The authors used retroviruses to introduce key genes into the skin cells, directly reprogramming them into neurons.

Compared with converted cells from healthy people, those from patients with disease-related mutations produced higher levels of a protein fragment called amyloid- $\beta$, which is linked to Alzheimer's disease. All reprogrammed neurons contained amyloid precursor protein - which is clipped to make amyloid- $\beta$ - but in cells from people with Alzheimer's mutations this protein was more localized in membranebound sacs.

Cell 146, 359-371 (2011)

\section{Fabric that puts out fire}

A specially treated cotton fabric can actively extinguish flames when it is set on fire.

The material was produced by Jaime Grunlan at Texas A\&M University in College Station and his colleagues by dipping the fabric repeatedly into two different solutions of water-soluble polymers, creating a coating just hundreds of nanometres thick. When heated to high temperatures, this layered, 'intumescent' film reacts to form a carbon-based foam that lowers the amount of gas fuelling the burn and slows heat transfer, inhibiting ignition. Flame testing showed that whereas the material burned when coated with just five protective layers (pictured, left panel), 20 layers were sufficient for it to put out the flame soon after ignition (right panel).

Such coatings may provide

COMMUNITY CHOICE

The most viewed papers in science

\title{
Hot cities heat up China
}

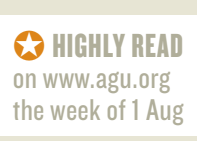

known as the urban heat island effect.

Baode Chen at the Shanghai Typhoon Institute and his colleagues analysed monthly mean temperature data from 463 meteorological stations in a range of urban and rural settings between 1981 and 2007. Using both raw and reanalysed data, the team found that urbanization contributed up to $44 \%$ of the temperature increase (almost $0.4^{\circ} \mathrm{C}$ per decade) in metropolises with populations of more than 1 million. The largest increase in the urban heat island effect came after the early 2000s, coinciding with a period of rapid growth of cities in China.

J. Geophys. Res. http://dx.doi.org/10.1029/2010JD015452 (2011)

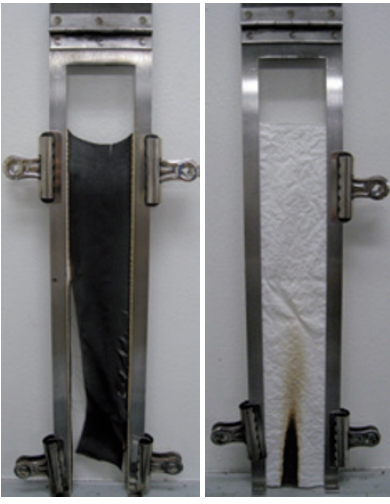

an alternative to chlorinated or brominated flameretardant chemicals, which persist in the environment if they leach from fabrics, and show signs of toxicity in animal studies.

Adv. Mater. http://dx.doi. org/10.1002/adma201101871 (2011)

\section{DEVELOPMENT}

\section{Placenta protects the brain}

Far from being simply a passive supplier of food, the mouse placenta protects the developing fetus from brain damage if the mother is deprived of food.

Kevin Broad and Barry Keverne at the University of Cambridge, UK, studied developing embryos and placentas taken from mothers that had gone 24 hours without food about midway through gestation - a stage in pregnancy that is crucial for the development of a brain region called the hypothalamus. The authors found shifts in gene expression, including upregulation in the placenta of genes involved in autophagy, a process by which cells degrade their own components. Meanwhile, in the hypothalamus the expression of genes linked to neural development was enhanced.

The authors suggest that the placenta breaks down its own tissues, recycling proteins inside its cells to provide a steady supply of nutrients to the developing hypothalamus.

Proc. Natl Acad. Sci. USA http://dx.doi.org/10.1073/ pnas.1106022108(2011) For a longer story on this research, see go.nature.com/ ej2kxh

\section{DNATURE,COM}

For the latest research published by Naturevisit:

www.nature.com/latestresearch 